\title{
Studies of seismic microzonation in Latium region (Italy) by experiencing the application of official guidelines in intra-mountain plains
}

\author{
A. Colombi ${ }^{1}$, S. Hailemikael ${ }^{2}$, G. Martini ${ }^{2}$, S. Martino ${ }^{3}$, \\ A. Paciello ${ }^{2}$, A. Peloso ${ }^{2}$, L. Salvatori ${ }^{4}$, G. Scarascia Mugnozza ${ }^{3}$ \\ \& V. Verrubbi ${ }^{2}$ \\ ${ }^{1}$ Latium Region, Environmental Direction Staff Office, Rome, Italy \\ ${ }^{2}$ Italian National Agency for New Technologies, \\ Energy and Sustainable Economic Development (ENEA), Rome, Italy \\ ${ }^{3}$ Department of Earth Sciences, University "Sapienza" of Rome, Italy \\ ${ }^{4}$ Department of Civil Protection and Centre for Research CERI, \\ University "Sapienza" of Rome, Italy
}

\begin{abstract}
In 2010, the Latium Regional Administration promoted a systematic study for the seismic microzonation of its Municipalities, according to the official national and regional guidelines. This activity was co-funded by the National Department of Civil Protection (DPC) following the issue of the National rule OPCM 3907/2010. A Working Group including researchers from Latium Regional Administration, ENEA and the Department of Earth Sciences of the 'Sapienza' University of Rome performed the studies in some municipalities characterised by the most severe level of seismic hazard. The activity was carried out on the basis of both archive geotechnical data and original geophysical surveys. The whole municipal territory was divided in stable areas, where no further analysis is required, and areas prone to stratigraphic or topographic amplification, as well as to earthquake-induced phenomena such as landslides, sinkholes, liquefaction and seiche. The experienced approach highlighted some critical features in the microzonation methodology that encourage the refinement of the operative procedures.
\end{abstract}

Keywords: seismic microzonation, stratigraphic amplification, topographic amplification, HVSR analysis, earthquake-induced phenomena. 


\section{Introduction}

The seismic microzonation (MS) is a useful tool for territorial planning applied to municipal general development plans in the aim of seismic risk mitigation. The main goal of MS is to bound and characterise areas having a homogeneous seismic response in terms of local amplification as well as areas prone to earthquake-induced instabilities.

Following the 2009 L'Aquila seismic sequence, the Italian Government ruled a "National Plan for the seismic prevention", funding together with Regional Administrations a series of actions devoted to the reduction of the vulnerability of strategic structures (e.g. public buildings, hospitals, schools) and a systematic application of MS methodology to the Italian territory.

The here reported results represent an application of the official document "ICMS - Seismic microzonation guidelines and criteria" (Working Group MS [1]) by DPC and the Latium regional Guidelines for seismic microzonation studies (DGR Lazio n. 545/10 [2]). The test sites, corresponding to some intramountain municipalities of the Italian Latium region, are reported in the following fig. 1.

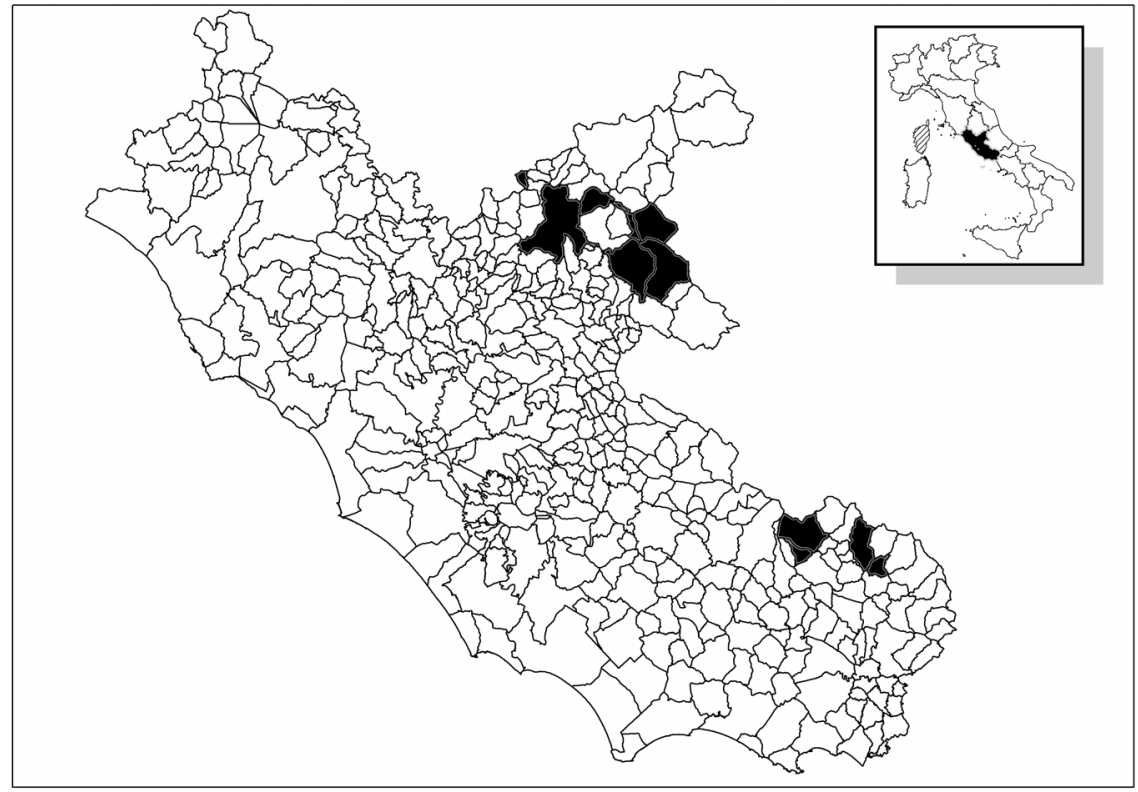

Figure 1: Test site locations: Rieti, Antrodoco, Borgo Velino, Fiamignano and Petrella Salto (in the NE sector of Latium Region), Alvito, Gallinaro, Isola del Liri and Sora (in the SE sector of the Latium Region).

Different types of microzones were identified and characterized according to the Microzonation Level 1 of the above quoted ICMS document. 
Rather than describing in detail the performed analyses, the Authors would here highlight some critical features which were observed during the application of the MS approach; they regard: i) identification criteria of the stable areas, ii) use of noise records analysis, iii) definition of the areas prone to topographic amplification and iv) characterisation of earthquake-induced phenomena, such as landslides, soil liquefaction and seiche involving intra-mountain lakes.

\section{Seismic microzonation (MS)}

The Italian guidelines for MS analysis set 3 levels of study: i) Level 1 has the purpose to identify and qualitatively characterise the areas deemed prone to seismic amplification or instabilities; ii) Level 2 aims at reaching a quantitative assessment of the amplification factors to be associated to each area, by the use of abacuses or simplified approaches; iii) Level 3 aims at quantifying the local seismic response by evaluating the amplification factors through numerical modelling.

The present study was focused on the application of the Level 1 methodology in intra-mountain areas. The whole territory of each considered municipality was zoned distinguishing: a) stable areas; b) stable areas susceptible of seismic amplification; c) unstable areas.

A first stage of activity consisted in the reconstruction of an engineeringgeological model of the subsoil, with the aim of defining the geometrical setting of soil deposits and their geotechnical properties, as well as the jointing conditions of the outcropping rock masses.

On this purpose, the available geological and geotechnical maps, together with literature and archive papers and geotechnical reports, were collected, analysed and eventually completed through specific in-field surveys. A particular attention was devoted in collecting and re-interpreting borehole stratigraphies, especially for identifying and reconstructing the seismic bedrock location. The subsoil reconstruction was supported by geological cross-sections and stratigraphic co-relation schemes for pointing out vertical and lateral juxtaposition of the deposits.

Geophysical surveys such as ambient noise and MASW measurements were moreover performed to point out resonance effects and estimate the shear wave velocity (Vs) of the deposits.

Landslides, active and capable faults, and areas prone to differential failure, liquefaction phenomena, sinkholes or seiche were bounded based on pre-existing databases [3-6] and the other available data. For each area prone to seismic amplification, a representative soil column was proposed for the following MS studies (Level 2 or 3).

\subsection{Stable areas}

This category refers to areas where it is possible to assume the absence of seismic amplification phenomena. The ICMS document defines the "stable areas" according to the soil category "A" of the new Italian Building Code (NTC08 [7]), i.e. soil characterized by shear wave velocity greater than $800 \mathrm{~m} / \mathrm{s}$ 
and where the topographical surface has steepness less than $15^{\circ}$. These constrains should respectively exclude the occurrence of stratigraphic and topographic amplification effects. The Latium Region adopted different constrains $\left(\mathrm{Vs} \geq 700\right.$ and steepness less than $30^{\circ}$ ) through specific technical guides.

A critical aspect of this definition lies in the assumption that the occurrence of stratigraphic amplification is mainly guided by the Vs value of the deposits, while both numerical modelling and experimental data show that the presence of a significant impedance contrast between the soft-soil layers and the bedrock is an indisputable feature to observe amplification effects. Therefore, applying the ICMS criteria, zones prone to seismic amplification must be defined, even where both the ambient noise records and the reconstructed engineering-geological model of the subsoil indicate that the local conditions are not able to induce significant amplification effects of ground motion.

This situation was observed for the "Marnoso-Arenacea" Formation, a marly sandstone deposit widely outcropping both in NE and in SE sectors of Latium Region, which can reach a thickness of several hundreds of meters and is characterised by variable stiffness (and consequently Vs values), due to its heterogeneity. Several noise measurements analysed through HVSR (Horizontal to Vertical Spectral Ratio) technique indicate the lack of resonance and, consequently, a "seismic stability" of the area, even when the Vs of the outcropping deposit is lower than $700 \mathrm{~m} / \mathrm{s}$ (fig. 2).

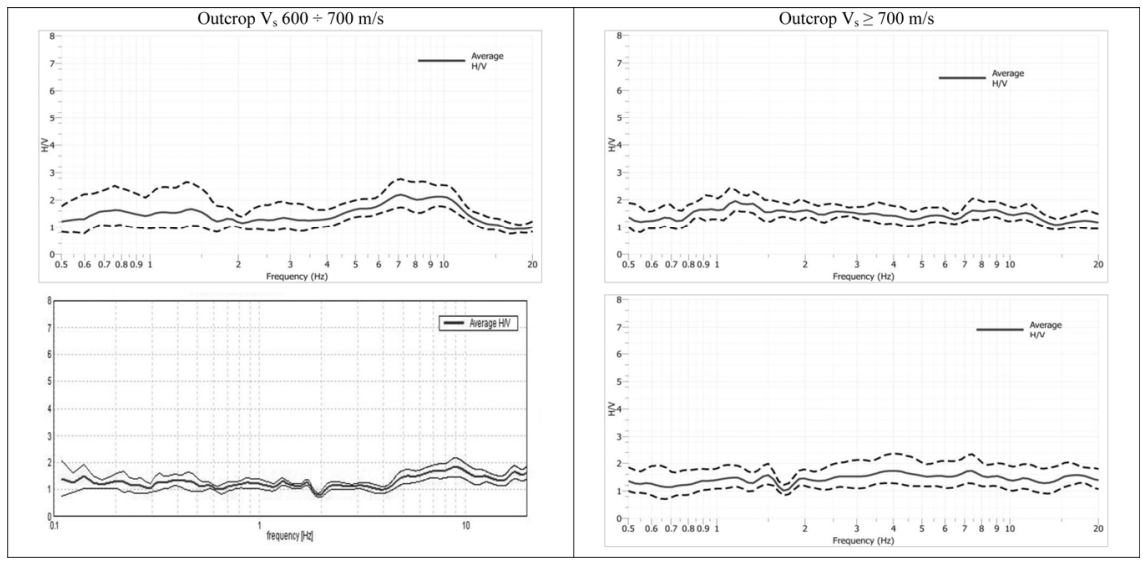

Figure 2: $\quad$ Example of HVSR from single station noise measures obtained on the same marly sandstone lithology ("Marnoso-Arenacea" Formation) outcropping in different areas of Latium region with Vs values $<700 \mathrm{~m} / \mathrm{s}$ (left) and $\geq 700 \mathrm{~m} / \mathrm{s}$ (right). The spectral ratios never point out any resonance effect.

Similar results had been already obtained by the Authors in other areas of Central Italy (e.g. [8]), not only from noise measurements, but also taking into 
account receiver functions or spectral ratios to a reference site of weak-motion records.

\subsection{Stable areas susceptible of seismic amplification - use of HVSR technique}

In Level 1 of the MS studies, the dynamic properties of the subsoil deposits can be derived by available data (e.g. down-hole or cross-hole investigations, geophysical investigation performed by array or single point measurements, etc.), which can be eventually completed by specific geophysical surveys. The Nakamura technique [9] is worldwide applied for microtremor analysis to point out resonance effects which can indicate stratigraphic amplification. We want to remark that one can be confident in this technique only when it is applied in 1D condition and in absence of velocity inversions in the subsoil deposits. In different conditions it could be useless or misleading.

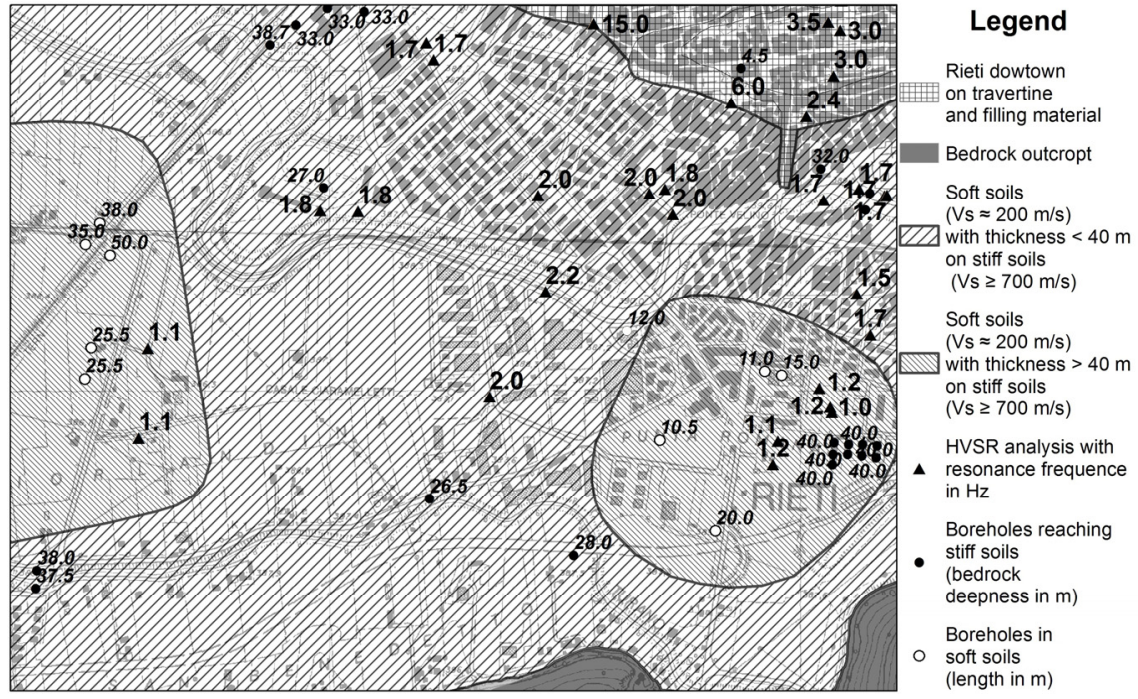

Figure 3: Comparison between geotechnical information and HVSR analysis in the alluvial plan of Rieti (NE sector of Latium Region). The resonance frequency values of soft soils can guide in the zonation of the areas with different thickness of the deposits.

In the case of the 1D stratigraphic sequence and a relevant Vs contrast with the underlying seismic bedrock, the HVSR technique provides a reliable resonance frequency $\left(\mathrm{f}_{0}\right)$ of the soft layer. This parameter is related to the thickness of soft soils (Ibs-von Seht and Wholenberg [10]) and can guide in the geological zonation. Fig. 3 shows the case of Rieti alluvial plain, where silt and sand deposits with an average $\mathrm{Vs} \approx 200 \mathrm{~m} / \mathrm{s}$ lie above gravels with $\mathrm{Vs} \geq 700 \mathrm{~m} / \mathrm{s}$. The borehole stratigraphy and the $f_{0}$ values agree with the presence of two areas 
where the soft soil thickness is higher than $40 \mathrm{~m}\left(\mathrm{f}_{0}=1.1-1.2 \mathrm{~Hz}\right)$, while the thickness decreases in the middle area $\left(\mathrm{f}_{0}=1.8-2.0 \mathrm{~Hz}\right.$; thickness $\left.=25-38 \mathrm{~m}\right)$. In presence of more complex stratigraphic sequences, while the HVSR technique cannot be directly applied, the HVSR curves, together with the horizontal and vertical spectra of ambient noise, can still provide useful information on the stratigraphic setting of the subsoil. Fig. 4 shows an example of surface geology where outcropping travertine deposits pass to softer alluvial deposits and the results of the related ambient noise records. The spectra of the vertical component show a peculiar behaviour, with peaks that make the HVSR function of difficult interpretation; however the visual inspection of HVSR curve and single component spectra indicates three kinds of typical shapes and allowed to define the surface geology in the downtown area of Rieti: i) Type A corresponding to travertine, with a particular trend of the vertical component and the absence of clear resonance peak; ii) Type $\mathrm{C}$ showing a clear peak in HVSR diagram, also confirmed by weak-motion records, in spite of the high peak on the vertical component spectrum; iii) Type B located near the stratigraphic contact between travertine and alluvial deposits. In this case both spectra and HVSR show an intermediate pattern, probably due to the interlayered presence of travertine and alluvium.

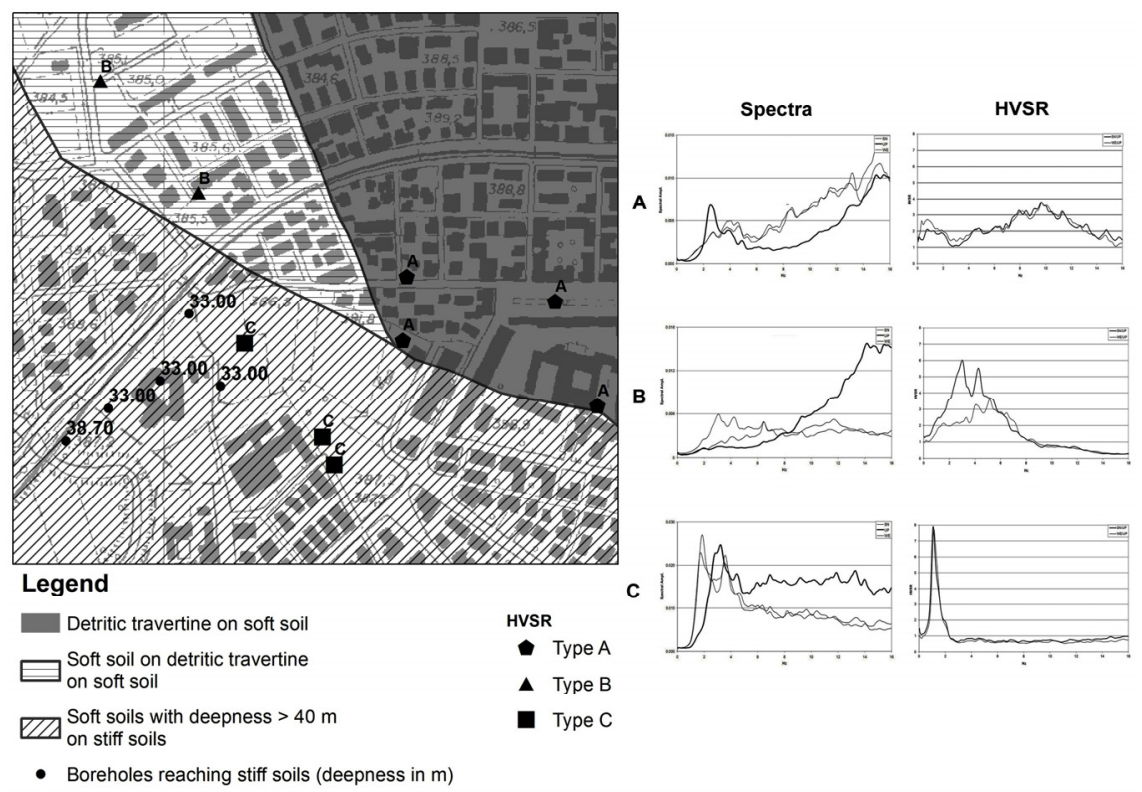

Figure 4: Example of ambient noise results in Rieti area, which provided useful information for reconstructing the geological model of the subsoil. In this case, spectral and HVSR functions indicate areas characterised by different local seismic behaviour (Groups A, B and $\mathrm{C}$ ) which is strictly related to the local geological setting. 


\subsection{Topographic amplification}

Based on the definition of "stable areas" from ICMS document (i.e., outcrop of poorly fractured rock with $\mathrm{Vs} \geq 800 \mathrm{~m} / \mathrm{s}$ and slope $\leq 15^{\circ}$ ) slope dip greater than $15^{\circ}$ must be considered as prone to topographic amplification of ground motion. As already mentioned, this constraint was modified to $30^{\circ}$ by the Latium Region guidelines.

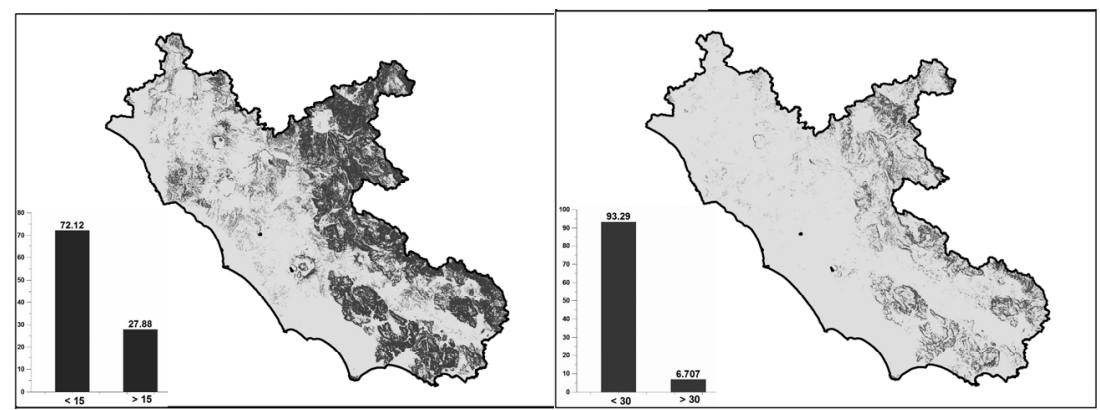

Figure 5: Areas in Latium Region characterized by different classes of slope dips. Left: $\leq 15^{\circ}$ and $>15^{\circ}$; Right: $\leq 30^{\circ}$ and $>30^{\circ}$.

Considering the Latium Region, fig. 5 shows the distribution and statistics of slopes with different classes of acclivity. In the two cases, $28 \%$ of territory with slope $>15^{\circ}$ (fig. 5 , left) and $6.7 \%$ of territory with slope $>30^{\circ}$ (fig. 5, right) must be classified as prone to topographic amplification, without any connection to local geology.
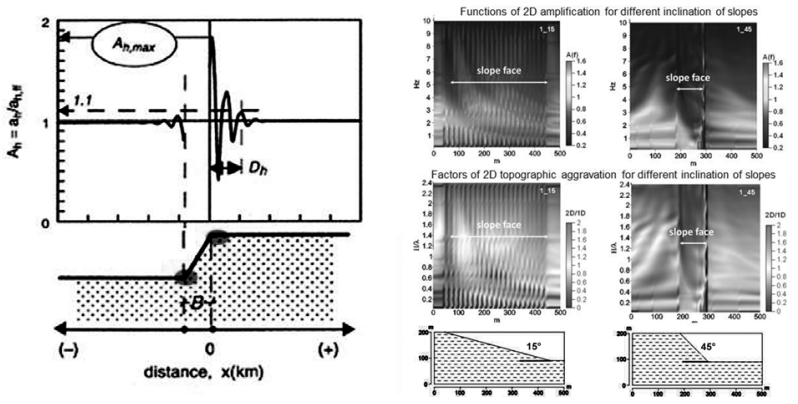

Figure 6: Example of theoretical analysis of topographic seismic amplification; left from Bouckovalas and Papadimitriou [11]; right from Lenti and Martino [12].

Anyway, irrespective of the fixed boundary value, the Authors would propose a different criterion, since theoretical studies (fig. 6) highlight the importance of slope changes rather than the topographic shape, whatever the dip, in the generation of local seismic amplification.

This is a particularly critical feature of the present seismic microzonation approach which it is encouraged to be emended after further and specifically devoted studies. 


\subsection{Unstable areas}

The MS methodology requires the individuation of areas prone to differential subsidence, soil liquefaction, sinkhole and landslides, or located near active and capable faults, since they can be regarded as "unstable areas".

The first two effects can be mainly controlled by the stratigraphic and geotechnical properties of the deposits. In particular, soil liquefaction requires the existence of cohesionless and saturated soils whose dynamic strength is mainly due to the particle internal friction (granular deposits, e.g. sand and silt). In the considered test sites such deposits were encountered in Isola del Liri municipality (SE sector of Latium Region (fig. 1)) where Pleistocene-Holocene travertine thresholds allowed the deposition of silty-sandy alluvial sediments within low-energy pools or fluvial islands.

For Level 1 of the MS, only a qualitative description of liquefaction susceptibility is required. On the other hand to perform a quantitative evaluation of the liquefaction potential, i.e. by computing a Liquefaction Index, more detailed geotechnical investigations are needed. In this regard a particular attention should be focused on the spatial distribution of the local geotechnical parameters, obtained by direct log stratigraphies (e.g. borehole data) or indirect in-site investigations (static or dynamic penetrometric tests, dilatometric tests, etc.).

Another typology of unstable area corresponds to landslides, which widely involve the studied areas. Available data were collected from both literature and archived databases, and eventually verified by direct in-field surveys.

As in the case of liquefaction susceptibility, Level 1 of the MS requires only a qualitative description of landslide distribution, i.e. mainly devoted to their classification in terms of rupture mechanisms (e.g. rockfall, topples, rotational/translational slides, lateral spreads) and state of activity (e.g. active, dormant, inactive). On the contrary, at the next levels a quantitative analysis of the expected landslide mobility (i.e. including first time activations or existing landslide re-activation) is requested by a simplified (Level 2) or deterministic (Level 3) approach.

Unstable areas can be also related to the effects of seismic shaking involving intra-mountain lakes, namely the earthquake-induced "seiches" (i.e., lake tsunamis). This effect represents another critical feature of the present ICMS release, since no specific procedure of analysis is reported for its characterization.

Generally speaking, the water waves that can be induced by an earthquake in a closed or half-closed water basin refers to: i) "free seiche" or tsunamis directly produced by fault displacements or by landslides; ii) seismically-induced or "forced seiche", i.e. due to the propagation of seismic waves. (Ichinose et al. [13]; Barberopoulou et al. [14]). Several examples of such a kind of seismic effect are reported in literature (e.g. Lisbona 1755, Alaska 1964-Mw=9.2; Denali $2002-\mathrm{Mw}=7.9)$ together with analytical methods for modelling the genesis and the evolution of water waves. 


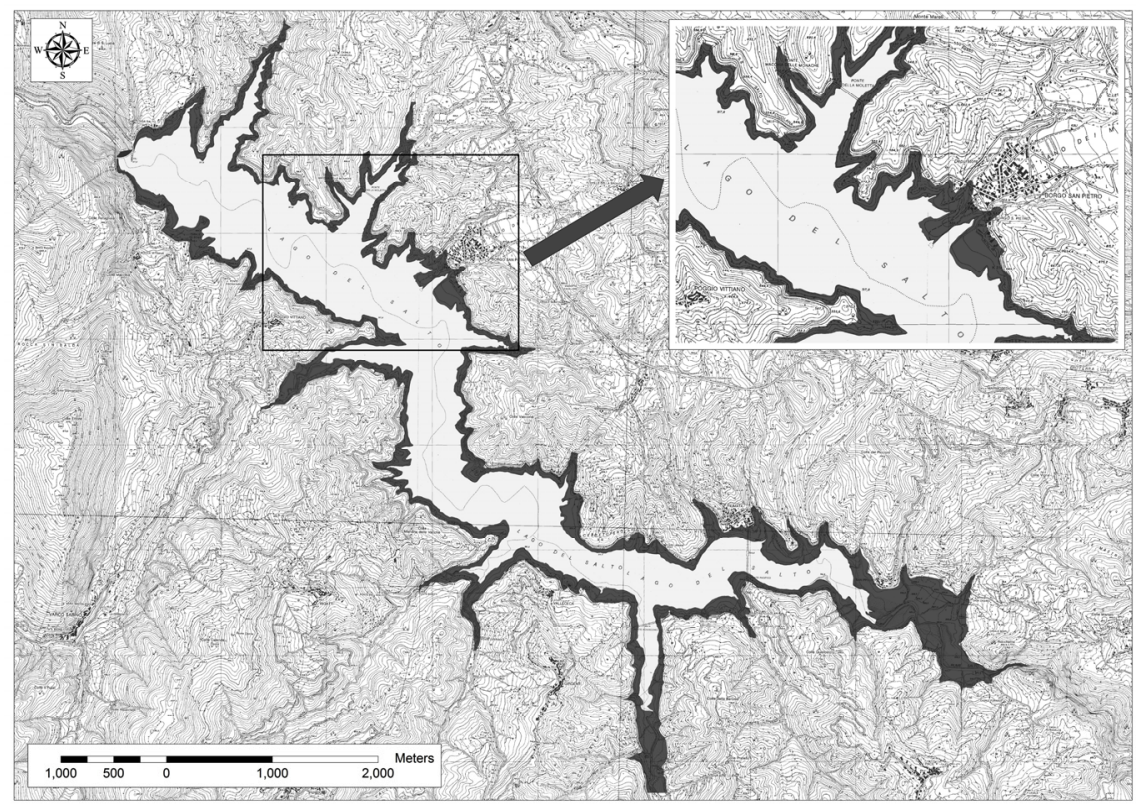

Figure 7: Area susceptible of inundation due to seiche in an intra-mountain artificial lake (Lago del Salto, NE sector of Latium Region).

A bibliographical research focused on this subject has shown that the study of lake waves due to fault movements or the passage of seismic waves in a water body needs complex and specific scenario analysis which goes beyond the detail requested by the Level 1 of MS. However, an expeditious method proposed by Slingerland and Voight [15] has been selected in order to evaluate the maximum height of the water wave due to a landslide sliding into a lake. This is obtained by a linear regression that considers the kinetic energy of the mass movement as a function of the landslide velocity.

The Lago del Salto artificial lake, generated after the build-up of a concrete dam in the first half of the XX century, is located (fig. 7) in the here studied NE sector of Latium Region. On the southern coast of the lake the "Marnoso Arenacea" Formation, which is involved in several landslide events, widely outcrops. A row evaluation of the landslide maximum dimension for this area gives volumes of about $5 * 10^{6} \mathrm{~m}^{3}$. The maximum height of water waves correspond to about $15 \mathrm{~m}$ over the average level of the lake. The area susceptible of inundation is reported in fig. 7 as a grey band all around the lake coastline.

Finally, with reference to active or capable faults, i.e. faults which have shown evidence of activity during the last 40,000 years and which are considered capable to cause ground failures, the ruled methodology indicates the need of consulting studies carried on by experts in the field. For Latium Region, the official guidelines establish the use of ISPRA - ITHACA (ITaly HAzard from CApable faults) database [4]. 


\section{Conclusive remarks}

The recent application of seismic microzonation studies in the Latium Region, is ruled by the Italian official guidelines (ICMS technical document by the National Department of Civil Protection) and Latium Administration regional Guidelines. MS is a useful tool for a correct land planning in seismic hazard mitigation perspective, however, the use of the current standard methodology in intramountain sedimentary basins pointed out some critical features, which mainly regard the definition of stable and unstable areas.

The identification of areas susceptible of amplification only based on the Vs values and not necessarily associated to significant seismic impedance contrasts, seems a questionable approach. As a perspective, further specific studies could lead to a more constrained definition of the areas prone to stratigraphic amplification.

Similarly, in the case of topographic amplification effects, it seems that the present definition, only based on the slope dip, cannot be regarded as exhaustive to provide a reliable assessment of the susceptibility to such effects. It has been already theoretically demonstrated the importance of slope changes rather than steepness on the local seismic response.

About the seismically-induced phenomena, an expeditious method was applied to evaluate the maximum height of the seiche due to a landslide sliding into a lake.

A final remark regards the use of HVSR technique at Level 1 of the MS studies. The experienced approaches demonstrated a great reliability of this method in case of simple and 1D geological subsoil model while, in case of more complex geological setting, the methodology can be useless or misleading. It was however shown that, in some of these complex conditions, a contemporary analysis of single component spectra and $\mathrm{H} / \mathrm{V}$ ratios could provide useful information on local stratigraphic conditions.

\section{Acknowledgements}

The Authors wish to thank Prof. Roberto W. Romeo, Leonela Bruni, Michele Lancia, Mirko Mento, Rocco Morrone, Attilio Porchia, Klodian Skrame and all Municipalities where the studies were carried out, for their fundamental support in executing the in-field surveys and in collecting and processing the technical data.

\section{References}

[1] Working Group MS, Seismic microzonation addresses and criteria. Civil Protection Department and Conference of Regions and Autonomous Provinces, Rome, 3 vol. and Dvd, 2008.

[2] DGR Lazio n. 545/10, Approvazione delle Linee Guida per l'utilizzo degli Indirizzi e Criteri generali per gli studi per gli studi di Microzonazione Sismica nel territorio della Regione Lazio di cui alla Deliberazione 387/09. 
Bollettino Ufficiale Regione Lazio n. 48 del 28 dicembre 2010 Supplemento 212, Rome, 2010.

[3] Fortunato C., Martino S., Prestininzi A. \& Romeo R.W., New release of the Italian catalogue of earthquake-induced ground failures (CEDIT), Italian Journal of Engineering Geology and Environment, 2, pp. 63-74, 2012.

[4] ITHACA, sgi.isprambiente.it/geoportal/catalog/content/project/ithaca.page

[5] Italian National Sinkhole Database, http://sgi2.isprambiente.it/sinkhole/

[6] Meloni F., Nisio S., Ciotoli G., Liperi L., TonelliV. \& Zizzari P., I sinkholes nella Regione Lazio alla scala 1:250.000. Catalogo 2011 - Su carta geologica informatizzata della Regione Lazio (2012). Online. http://sgi2.isprambiente.it/sinkhole/news/Carta_sinkholes/carta_sinkhole_la zio.htm

[7] NTC08, Norme tecniche per le costruzioni. Ministero delle Infrastrutture e dei Trasporti, Decreto Ministeriale del 14 gennaio 2008, Supplemento ordinario alla G.U. n. 29 del 4 febbraio 2008.

[8] Scarascia Mugnozza G. (ed.). La pericolosità sismica nel Lazio. Pericolosità sismica di base, analisi di risposta sismica locale e studi per la microzonazione sismica, Italian Journal of Engineering Geology and Environment - Book Series, Casa Editrice Università La Sapienza, Rome, 2011.

[9] Nakamura Y., A method for dynamic characteristics estimates of subsurface using microtremor on the round surface, Quarterly Report of RTRI, pp. 25-33, 1989.

[10] Ibs-von Seht M. \& Wholenberg J., Microtremor measurements used to map thickness of soft sediments. Bulletin of the Seismological Society of America, 89, pp. 250-259, 1999.

[11] Bouckovalas G. D. \& Papadimitriou A. G., Numerical evaluation of slope topography effects on seismic ground motion. Soil Dynamics and Earthquake Engineering, 25, pp. 547-558, 2005.

[12] Lenti L. \& Martino S., The LEMA_DES approach for deriving dynamic equivalent signals: numerical modeling of input-slope interaction. Proc. $14^{\text {th }}$ European Conference on Earthquake Engineering (ECEE), Ohrid (Macedonia) 30-08/03-09, n471, pp. 1-9, 2010.

[13] Ichinose G. A, Anderson J. G., Satake K., Schweickert R. A. \& Lahren M. M., The potential hazard from tsunami and seiche waves generated by large earthquakes within Lake Tahoe, California-Nevada, Geophysical Research Letters, 27, pp. 1203-1206, 2000.

[14] Barberopoulou A., Qamar A., Pratt T. L. \& Steele W. P., Long-Period Effects of the Denali Earthquake on Water Bodies in the Puget Lowland: Observations and Modeling. Bulletin of the Seismological Society of America, 96(2), pp. 519-535, 2006.

[15] Slingerland R \& Voight B., Evaluating Hazard of Landslide-Induced Water Waves, J. Waterways, Pact, Coastal and Ocean Div. ASCE, 108(WW4), pp. 504-512, 1982. 